\section{BRIEF NOTES OF INTERESTING CASES OF CRANIAL SURGERY.}

BY HENRY CURTIS, B.S. LOND., F.R.C.S. ENG.,

ASSISTANT SURGEON TO THE METROPOLITAN HOSPITAL, KINGSLANDROAD, N.E.; TO THE BRANCH SEAMEN'S HOSPITAL, ROYAL ALBERT DOCK, E.; AND SENIOR CLINICAT ASSISTANT IN THE EAR AND THROAT DEPARTMENTS OF THE LONDON HOSPITAL, E.

A PAPER read at the Medical Graduates' College and Polyclinic, London, on March 3lst last with the above title included the records of six patients under my care, arranged in four groups. A few brief notes in abstract of the longer communication will, I trust, be of interest to readers of THE LANCET.

Group 1.-The first group comprised two cases of depressed fracture of the skull with extra- and intra-dural effusion, one of which was compound and complicated with two separate and extensive fractures on the same side of the vertex. In the first of these the lesion was in the left parietal region, causing aphasia and right-sided hemiplegia, clearing up after removal of the pressure, at least 48 hours after the injury.

The second case contrasted with the other in that whilst there were two extensive depressed fractures there was practically no shock and no paralysis or functional disturbance, though the injuries were severe enough to cause considerable effusion. This was probably the result of the pressure being applied chiefly to the frontal lobe. A brief reference was made to the use of lumbar puncture, the cerebro-spinal fluid in extradural hæmorrbage being clear, whereas it is blood-stained in extradural hæmorrhage from cerebral laceration or torn sinus.

Group 2.-A case of gumma of the pericranium and sub. jacent left parietal bone, occurring at the seat of repeated injury and causing tenderness and severe head. ache of several years' duration. The growth was of about the size and shape of an adult human patella. Complete disappearance of the headache was noted on the day after removal by trephining, \&c.; iodide was administered, and there was no subsequent recurrence.

The facts illustrated by this case were: (1) that though the spirochæte of syphilis produces a generalised infection, it shows a well-marked tendency to settle in certain tissues or organs, and, amongst bones, notably the skull; and (2) that exposure of these tissues or organs to injury by creating an area of still lower vitality than usual greatly increases their liability to gummatous deposit. This is comparable with the fact that no effect may be produced on inoculating an animal with staphylococcus from a virulent lesion in man until an area is met with or created where the resistance has been lowered, such as the site of a fracture.

Another instance of this was afforded in my lecture on Liver Abscesses at the Polyclinic last year. Dysentery led to amoebic abscesses of the liver rupturing through the lung, there being also an associated appendix abscess. As the result of free drainage recovery was progressing when the most profuse discharge set in, the prognosis becoming almost hopeless. Potassium iodide, pushed to 35 grains four times a day for 29 days before iodism occurred, resulted in rapid and permanent recovery by absorbing the gummata which were complicating the liver abscess.

In making a diagnosis the patient's occupation should always be borne in mind. In the two instances here alluded to both men had been in the army, and specific trouble may be aptly, if a little unkindly, included amongst the " Diseases of Occupation." Allusion was made to the danger of leaving alone any sequestrum resulting from necrosis of the outer table, perforation of the skull leading to fatal meningitis or cerebral abscess being recorded (see Fig. 84, Vol. I., Treves's "System of Surgery").

Groups 3 and 4.- The last two groups of cases comprised (a) a case of suppurative mastoiditis and cerebral abscess in which the cardinal symptoms of abscess were completely masked by those due to thrombosis of the bulb of the jugular vein, and there was no optic neuritis; and $(b)$ two cases of pneumococcic meningitis, one supervening upon pneumonia, the other resulting from infection from the tonsils, lateral sinus thrombosis preceding the meningitis, a noticeable feature being absence throughout of rigors.

A brief recital of the cardinal symptoms of the chief complications of middle-ear and mastoid disease followed and it was seen that absence of optic neuritis is of no value in excluding cerebral or cerebellar abscess, that rigors are highly significant of thrombosis, which if not present in the lateral sinus itself will be found in the bulb of the jugular vein, though, again, the absence of rigors does not negative sinus thrombosis, as was illustrated in one of the present cases. High leucocytosis and high percentage of poly. morphonuclears when present are of supreme importance as evidence of sepsis generally, if not of intracranial sepsis; in cerebral abscess, other signs pointing that way, 80 per cent. polymorphonuclears and over would be diagnostic (Potts). It is of equal value for the same reason in lateral sinus pyæmia, but was absent in the second of the two cases of pneumococcic meningitis and thrombosis, the blood count being only 10,000 per cubic millimetre $(5,000$ to 10,000 leucocytes being within the normal range). The ideal treatment of the mastoid-cerebral abscess case where the symptoms were masked was outlined.

In conclusion, more active treatment of meningitis, septic and tuberculous, was urged, the diagnostic and therapeutic value of lumbar puncture being reviewed, and recent suggestions for the treatment of these otherwise generally fatal cases were summarised. These.were : 1 . Early bilateral drainage of the skull, perhaps with counter-opening of the lumbar spinal canal, to permit of continuous irrigation (Ballance). 2. Repeated lumbar puncture (Barker). 3. (Author's suggestion.) The use of appropriate vaccines, combined with lumbar puncture where necessary, either for diagnosis or to obtain material for the vaccine, or for the relief of urgent pressure or other symptoms. When the indication otherwise is clear, if lumbar puncture is negative, trephining would be justifiable, with a view to confirming the diagnosis, relieving the urgent symptoms, such as headache and optic neuritis, and securing material for vaccine treatment, if not otherwise obtainable.

With more active attempts at treatment of this kind, the writer hopefully anticipates the steady reduction in the mortality from meningitis and also a vast improvement in the prognosis in other diseases, in which so often it has hitherto proved the fatal complication.

\section{A METHOD OF SUTURING THE LATERAL RECTI TO INSURE GREATER MOBILITY OF THE STUMP AFTER ENUCLEA- TION OF THE EYEBALL.}

BY ERNEST CLARKE, M.D., B.S. LOND., F.R.C.S. ENG., SURGEON TO THE CENTRAL LONDON OPHTHALMIC HOSPITAL, GRAY'S INN ROAD, W.C.

AT the meeting of the British Medical Association in 1902 I read a paper on this subject illustrating the manner in which I recommended the operation to be performed. I have had considerable further experience of the great value of this method of removing the eye and have, moreover, improved on my original method.

As everyone knows, the method of enucleation mostly adopted and found described in almost every text-book is the simple and, it seems to me, careless plan of merely dividing the muscles and relying entirely on the attachment of these muscles to Tenon's capsule for the mobility of the stamp. Fisher says: "After a well-performed excision the anterior extension of Tenon's capsule still remains intimately adherent to the ocular conjunctiva and so enables the recti muscles to exercise their action upon the conjunctival socket and thus to produce the movements of the artificial eye." This, of course, is true, but the lateral movement of the stump resulting is nothing like so extensive as when these muscles are attached to the conjunctiva well over the middle line.

The method is as follows. The conjunctiva is opened all round the sclero-corneal margin and freely separated from the globe. The two lateral recti are then separately hooked up and thoroughly isolat6d from their attachments, clamped with a Prince's forceps, and finally divided close to the eyeball ; the other muscles are divided close to the eveball and the globe removed in the ordinary way, but especial care is taken to remove the eye as cleanly as possible. One of the lateral recti is then sutured with catgut to the lower lip of the conjunctival opening on the opposite side and the other 
rectus to the apper lip of the conjunctival opening on its opposite side. A thickish silk suture is passed through the margins of the conjunctival opening in the centre and not tied but simply twisted. This twisted thread, although enough to keep the lips of the conjunctiva in apposition, allows the egress of any blood which may accumulate within. The bleeding of the stump should be prevented or arrested by a few drops of adrenalin solution and by very firmly applying a sterilised pad. The bandage can be loosened and the dressing changed six hours after the operation and then the socket need not be re-dressed for 24 hours. At this later dressing the conjunctiva is pulled forward by the twisted suture and the parts gently bathed with a weak carbolic or some other antiseptic lotion. The twisted suture is entirely removed on the third day. If catgut is used for the suturing of the muscles they will require no further attention. The resulting stump forms a firm bed for the artificial eye and its lateral movements are very extensive.

It requires very little knowledge of mechanics to realise that if the superior and inferior recti are also sutured, as has been recommended, the lateral movements are somewhat impeded. A good lateral movement of the artificial eye is everything and nothing ought to interfere with this desirable aim. The up and down movements are of very little import, as the upper lid covers the eye in looking down and the patient rarely has to look up when being observed and can always avoid it by raising the head upwards. A weak alum lotion should be used to the stump when the parts are healed in order to harden the conjunctiva. A Snellen "solid eye" can be worn as early as four weeks after the enucleation.

Chandos-street, W.

\section{clinical 算otes:} MEDICAL, SURGICAL, OBSTETRICAL, AND
THERAPEUTICAL.

NOTE ON A CASE OF RUPTURED HEART.

By A. Martus Wilson, M.D., B.S. Durh., M.R.C.S. Eng., L.R.C.P. LOND.,

VISITING PHYSICIAN TO THE SOMERSET HOSPITAL, CAPE TOWN.

A EURopean woman, aged 50 years, unmarried, was admitted into the Somerset Hospital, Cape Town, under my care on Oct. 5th, 1906, complaining of pain in the chest over the centre of the sternum. There was no history of any previous illness. The catamenial history was from 19 to 33 years of age; the flow had been always slight in amount. From an outside practitioner it was learned that the illness had started ten days previously to admission to hospital with symptoms of a slight cerebral hæmorrhage attended by loss of consciousness for a few hours which was followed by a curious mental condition for some days. All this the patient herself had no knowledge of. There was no paralysis of any sort.

On admission the patient was quite rational and she presented no physical signs whatever beyond rather thickened arteries. As she had not menstruated for 17 years the menopanse was dismissed and the case was looked upon as being neurotic in character and the patient was kept under observation. On Oct. 12th, while sitting at table having afternoon tea with her friends, the patient suddenly gave a little cry and dropped dead. She was very cyanosed.

At the post-mortem examination there was evidence of small, fairly recent hæmorrhage in the posterior right frontal convolution in the cortical region about two inches from the central longitudinal fissure ; there was also a small area of softening containing yellowish fluid. The pericardium, which was enormously distended with blood-clot, was covered outside with injected capillaries, and was roughened over the aorta and the lower part of the left ventricle. The heart was normal in size. At the apex of the left ventricle there was a protuberance partly filled up with old blood-clot organised and adherent. In the middle of this was a small opening; outside diameter nine millimetres, inside diameter two millimetres. The left ventricle was thinned out here. The right ventricle was normal. The aorta was very slightly enlarged and showed numerous hard, calcareous, atheromatous patches, especially near the left carotid, which was itself a calcareous pipe. The abdominal aorta showed extensive atheromatous changes with ulcerated spots. There were no signs of syphilis anywhere and no foreign body was found in the viscera.

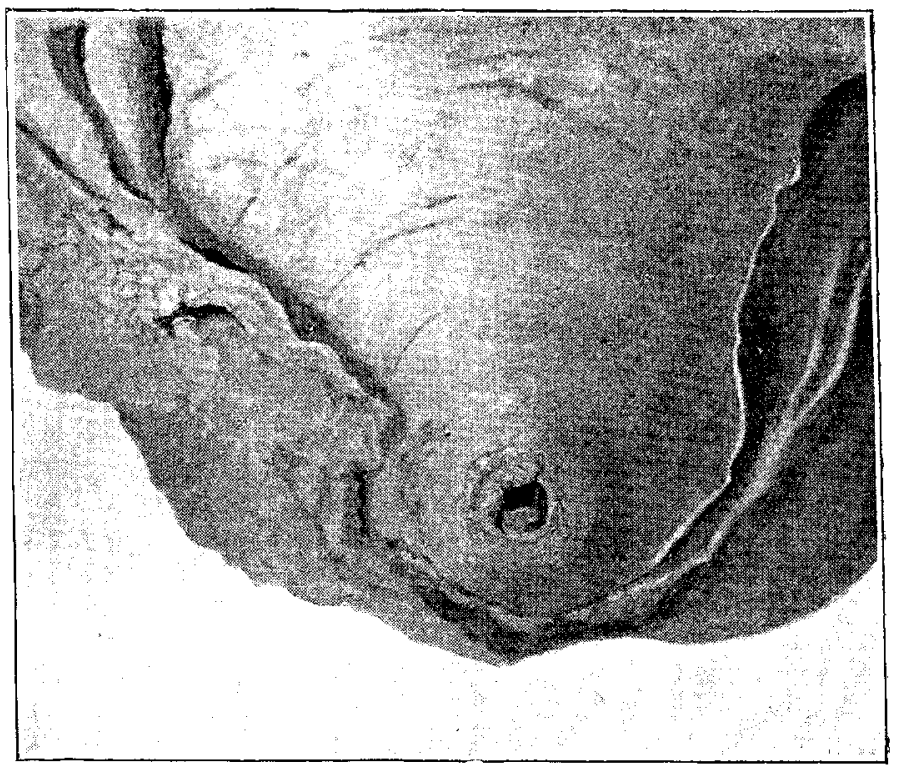

Apex of the left ventricle; pericardium turned aside to show opening of rupture. Drawn in perspective, actual size, by Walter D. Severn.

The accompanying illustration shows exactly the position and appearance of the rupture. I have not come across any record of such a case nor seen any specimen before this.

Cape Town.

\section{ACUTE HYDRAMNIOS IN UNIOVULAR TWIN} PREGNANCY.

By Edwin T. H. Davies, M.B., B.S. Lond., M.R.C.S. Eng., L.R.C.P. LOND.,

OBSTETRIC OFFICER TO ST. MARY's HOSPITAI, PADDINGTON, W.

THIS condition is sufficiently rare to be worth reporting. The patient was a multipara, 29 years of age, having had eight children and no miscarriages. The history was as follows. On April 20th she was seven and a half months advanced in a normal pregnancy. She was no bigger than she expected to be at the corresponding time of pregnancy. She went to bed that night in good health but during the night she had " much pain at the bottom of the back and could not rest at all." When she got up on the following morning she found that she "had got very much bigger all of a sudden" and that her garments were too small for her. She managed to get to the hospital, a six minutes' walk, that morning for a maternity letter but had much difficulty in returning home. She then went to bed and stayed there, not so much because of the pain but owing to the great discomfort. From the morning of April 21st until the time of delivery, a period of three days, the patient did not think that her abdomen had got any bigger. On April 24th definite labour pains set in, occurring every quarter of an hour to begin with but becoming less frequent. She looked tired and had a weak pulse of 100 . On examination of the abdomen I found it to be very large and too tense for any part of the foetus to be felt. There was a well-marked fluid thrill present. It felt as if she had a large ovarian cyst. On examination per vaginam $I$ found that the os was fully dilated and the membranes were unruptured, there being no fore-waters. There was a face presentation, with the hand prolapsed by its side in the pelvic cavity. I ruptured the membranes and pushed up the hand easily and to my surprise no liquor amnii came away. I then passed a catheter and drew off a few drachms of urine. Chloroform was then administered. I found the head to be small and that I could pass my hand beside it up above the brim. To the left side I found a bulging sac and pushed one finger through the thin wall; immediately there was a gush of liquor amnii which was allowed to drain away gradually. There was a premature child in the sac. The amount of liquor amnii was nine and a half 